\title{
Steric sea level variations inferred from combined Topex/Poseidon altimetry and GRACE gravimetry
}

\author{
D. García*, G. Ramillien, A. Lombard and A. Cazenave \\ LEGOS, Observatoire Midi-Pyrénées, Toulouse, France \\ *On live from Space Geodesy Laboratory, Applied Mathematics Department, EPS, University of \\ Alicante, Spain
}

\begin{abstract}
In this study, we propose to estimate the steric sea level variations over a $<2$ year period (April 2002 through December 2003) by combining global mean sea level (GMSL) based on Topex/Poseidon (T/P) altimetry with time-variable geoid averaged over the oceans, as observed by the GRACE (Gravity Recovery and Climate Experiment) satellite. In effect, altimetry-derived GMSL change results from two contributions: steric (thermal plus salinity) effects due to sea water density change and ocean mass change due to water exchange with atmosphere and continents. On the other hand, GRACE data over the oceans provide the ocean mass change component only. The paper first discusses the corrections to apply to the GRACE data. Then the steric contribution to the GMSL is estimated using GRACE and T/P data. Comparison with available thermal expansion based on in situ hydrographic data is performed.
\end{abstract}

\section{Introduction}

Global mean sea level (GMSL) variations results from two processes: (1) steric height variations (hereafter denoted $\mathrm{GMSL}_{\text {steric }}$ ) produced by dilatation/contraction of sea water via temperature and salinity change, and (2) variations of ocean mass due to water exchange with atmosphere, continental water reservoirs and land ice bodies. The ocean mass component is in the following denoted by $\mathrm{GMSL}_{\text {ocean mass. }}$ It comes out that: $\mathrm{GMSL}=\mathrm{GMSL}_{\text {steric }}+\mathrm{GMSL}_{\text {ocean mass. }}$

Long-term sea level rise measured by tide gauges over the past decades (e.g., Church et al., 2004, Holgate and Woodworth, 2004) and satellite altimetry since 1993 (e.g., Nerem and Mitchum, 2001, Leuliette et al., 2004) has been interpreted in terms of thermal expansion and ocean mass change using models and various observations (see Church et al., 2001 and Cazenave and Nerem, 2004, for reviews). Other studies, 
focusing on the annual mean sea level (Chen et al., 1998, Minster et al., 1999, Cazenave et al., 2000, Milly et al., 2003), showed that the non steric annual GMSL based on Topex/Poseidon (T/P) altimetry corrected for thermal expansion, is well explained by seasonal variations in atmospheric water vapor content and total land water storage (as estimated from outputs of global land surface models).

The newly launched GRACE (Gravity Recovery and Climate Experiment) mission, devoted to measure tiny variations of the Earth's gravity field (Tapley et al., 2004a,b, Wahr et al., 2004, Schmidt et al., 2005), now allows direct estimates of land water storage change over continental areas as well as ocean mass change over oceanic areas. The latter application has recently been presented by Chambers et al. (2004) who showed that the GRACE data averaged over the oceans closely follow the altimetryderived GMSL after correcting for steric effects, thus representing the ocean mass component due to change in atmospheric water, land hydrology and land ice mass. In the present study, we will estimate over a short time span (April 2002-December 2003), the steric sea level by combining GRACE data over the oceans with T/P-derived GMSL.

\section{Data and processing}

\subsection{Topex/Poseidon altimetry data}

GMSL is estimated from $\mathrm{T} / \mathrm{P}$ altimetry data distributed by the AVISO (Archiving, Validation and Interpretation of Satellite Oceanographic) data centre. We consider the period from April 2002 to December 2003. Conventional geophysical and atmospheric corrections (tides, wet and dry tropospheric corrections, ionospheric correction, sea state bias as well as instrumental drifts and bias) are applied to the data, as recommended by AVISO. We also apply the inverted barometer (IB) correction to account for atmospheric loading on sea surface, using the time-variable mean surface pressure averaged over the oceanic domain (e.g., Minster et al., 1999). The IB correction, at latitude $\varphi$, longitude $\lambda$ and time $t$, is expressed as: $-0.9948[p(\varphi, \lambda, t)-$ $\mathrm{P}(\mathrm{t})]$, where $\mathrm{p}(\varphi, \lambda, t)$ is the instantaneous local surface pressure and $\mathrm{P}(\mathrm{t})$ is the mean surface pressure spatially averaged over the whole oceanic domain. In this equation, the IB correction is in $\mathrm{cm}$ if $\mathrm{p}$ is in mbar. IB-corrected T/P sea level data are interpolated onto $1^{\circ} \mathrm{x} 1^{\circ}$ regular grids at 10 -day intervals (the duration of the $\mathrm{T} / \mathrm{P}$ orbital cycle), then spatially averaged between latitudes $60^{\circ} \mathrm{S}$ and $60^{\circ} \mathrm{N}$, using equi-area weighting, and further expressed as monthly means between April 2002 and December 2003. Errors 
associated with 10-day T/P GMSL values are estimated to be $\sim 4 \mathrm{~mm}$ (Nerem and Mitchum, 2001). For monthly values, we assume that the uncertainty is $4 / \sqrt{ } 3 \mathrm{~mm}$, thus $\sim 2.5 \mathrm{~mm}$.

\subsection{GRACE}

Launched in March 2002, the GRACE mission measures spatio-temporal gravity variations, providing direct monitoring of water mass change in the Earth system (Tapley et al., 2004a,b, Wahr et al., 2004). Here we focus on the ocean mass component that can be determined by considering the GRACE data over the oceanic domain. We use the GRACE L-2 products made available by the GRACE project (Level-2 Gravity Field Product User Handbook, S. Bettadpur, 2004a). These consist of monthly solutions of geoid spherical harmonic coefficients, up to degree and order 120, from April 2002 through December 2003. Note that several monthly solutions are missing (June 2002, July 2002, December 2002, January 2003 and June 2003).

During the GRACE data processing, several processes are modelled and their effects removed (see Bettadpur, 2004b, and Fletchner, 2003). In addition to solid Earth and ocean tides, other processes include an atmospheric loading model based on ECMWF (European Centre for Medium-Range Weather Forecast) surface pressure data and high-frequency ocean mass variations computed with a mass-conserving barotropic ocean model driven by high-frequency winds and atmospheric pressure (see Fletchner, 2003). Since we are interested into the total ocean mass signal, we restored the barotropic ocean model removed during the GRACE data processing, as recommended in Fletchner (2003). As mentioned in Chambers et al. (2004), the barotropic model is mass-conserving. Thus it cannot introduce a spurious signal into GRACE GMSL ocean mass as far as global average is concerned. However, we checked that missing the highlatitude ocean domain above $60^{\circ} \mathrm{N} / \mathrm{S}$, has a small, but non negligible effect on the GMSL $_{\text {ocean mass }}$ curve. We also restored the atmospheric loading model. Thus, over the ocean, the total GRACE signal, which now includes both atmospheric and oceanic loads, accounts for the IB effect (i.e., locally, any atmospheric pressure anomaly is cancelled by a corresponding ocean mass anomaly). However, for comparison with the IB-corrected sea level change based on T/P altimetry, we have to remove, from the GRACE signal, the $\mathrm{P}(\mathrm{t})$ term (i.e., mean atmospheric surface pressure averaged over the whole oceanic domain). In effect, this term is removed from the altimetry data when 
applying the IB correction. This is different from the GRACE data: when averaged over the oceanic domain, the sum of the restored atmosphere plus ocean loads, while cancelling locally the ocean response to atmospheric mass anomalies, leads to a non zero term, equal to $\mathrm{P}(\mathrm{t})$. It has thus to be removed to the GRACE data too.

GRACE data do not include degree 1 spherical harmonic coefficients. These terms represent the position of the Earth's center of mass in a terrestrial reference frame. To be consistent with the reference frame used for $\mathrm{T} / \mathrm{P}$, the degree 1 coefficients, which are estimated from the variations of the Earth's center of mass proposed by Chen et al. (1999), are added to the GRACE data.

The degree 2, order 0 coefficient, representing the Earth's oblateness (Cox and Chao, 2002), is not well observed by GRACE (Tapley et al., 2004a). Therefore, we use a better estimate of the degree 2, order 0 coefficient based on Satellite Laser Ranging observations (updated from Cox and Chao, 2002; Cox, personal communication, 2005).

Assuming that the gravity changes observed by GRACE are produced by mass changes at the surface of the Earth, the GRACE monthly geoid data can be converted into surface mass variations and expressed by equivalent water height (Wahr et al., 1998, Chao, 2005, Ramillien et al., 2005). In order to minimize the leakage error due to land water mass signal over the continents, a Gaussian filter as described by Swenson and Wahr (2002) was applied to the GRACE data over the $60^{\circ} \mathrm{S}-60^{\circ} \mathrm{N}$ ocean domain for each month from April 2002 through December 2003. We tested two Gaussian filter radii, $300 \mathrm{~km}$ and $1000 \mathrm{~km}$. In principle, the smaller the radius, the smaller the leakage. However, because of noise affecting higher degree spherical harmonic coefficients of the current GRACE solutions (Tapley et al., 2004a; Wahr et al., 2004), the $1000 \mathrm{~km}$ radius was chosen, which by definition removes all signal beyond degree 30 . Alternative approaches to process the GRACE data that aim at reducing the noise at high degrees, in order to improve spatial resolution, are currently explored by several groups. For example, Rowlands et al. (2005) reported an improvement by a factor of 3 in both temporal and spatial resolutions through a "mascon" analysis of GRACE data.

Errors associated with each spherical harmonics coefficient are released with the GRACE L-2 data. These errors are weighted similarly to the coefficients during the Gaussian filter processing. Then, the error associated to GRACE-derived GMSL ${ }_{\text {ocean mass }}$ estimate is computed as described in Swenson and Wahr (2002), which is estimated around $\sim 2 \mathrm{~mm}$. 


\section{Result}

\subsection{Combining GRACE and T/P altimetry data}

Fig. 1a, 1b, 1c presents the observed T/P GMSL, GRACE GMSL ${ }_{\text {ocean mass }}$ and the

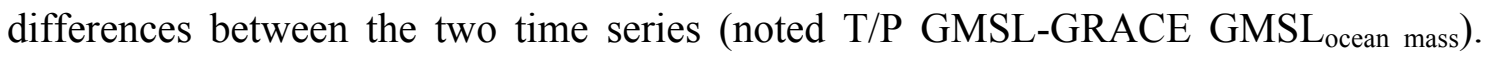
These curves are based on a spatial averaging between $60^{\circ} \mathrm{S}$ and $60^{\circ} \mathrm{N}$. The least-squares fitted annual amplitudes and phases of the three time series are presented in Table 1. The T/P GMSL has an annual amplitude of $6.1 \pm 1.2 \mathrm{~mm}$, and a phase of $309.7^{\circ} \pm 11.3^{\circ}$

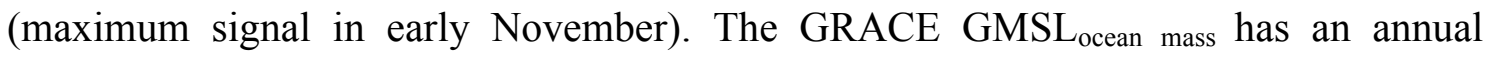
amplitude of $10.9 \pm 1.1 \mathrm{~mm}$ and a phase of $276.5^{\circ} \pm 7.8^{\circ}$ (maximum signal in early-

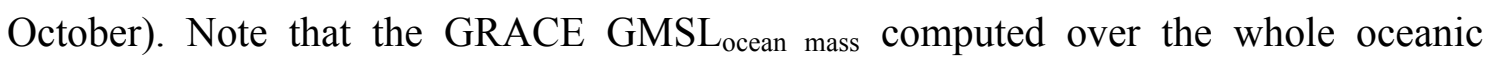
domain, which represents the total water budget exchanged between the ocean and the atmosphere/continents, has an annual amplitude of $10.0 \pm 2.3 \mathrm{~mm}$ and a phase of $282.1^{\circ} \pm 16.3^{\circ}$ (maximum signal in mid-October). Accounting for the global ocean surface, this signal represents a water mass variation of $6.86 \cdot 10^{12} \mathrm{~m}^{3}$ from peak to peak.

The annual amplitude of the difference curve is $6.4 \pm 2.1 \mathrm{~mm}$, with a phase of $72.7^{\circ} \pm 22.3^{\circ}$ (maximum signal on $15 \mathrm{March}$ ). In principle this difference curve represents the steric contribution to GMSL. The annual amplitude and phase of the residual curve compare well with published estimates of the steric annual sea level based on climatologies. For example, Chen et al. (1998), using WOA94 objectively analyzed temperature fields (Levitus et al., 1994), report an amplitude of $5.5 \mathrm{~mm}$ and a phase of $79^{\circ}$ (corresponding to $20 \mathrm{March}$ ) for the annual steric sea level cycle. Minster et al. (1999) and Cazenave et al. (2000), also using the Levitus et al. (1994) climatology, found an amplitude of $5 \mathrm{~mm}$ and a maximum signal on $12 \mathrm{March}$. Thus the result reported here by combining T/P GMSL and GRACE ocean mass appears to be consistent with values based on ocean data climatologies. 


\subsection{Steric sea level data}

We have compared the residual (T/P GMSL - GRACE GMSL ocean mass) time series with the steric sea level computed using the Ishii et al. (2006) global ocean temperature data. The latter data set consists of $1^{\circ} \times 1^{\circ}$ gridded temperature fields given as monthly means down to $700 \mathrm{~m}$, from 1945 to 2003 (see Ishii et al. 2003 and Ishii et al., 2006 for detailed descriptions). Unless using an ocean temperature climatology (i.e., based on data averaged over many years) as done in Chambers et al. (2004), the Ishii et al. data base is the only one providing monthly mean temperatures suitable for the short time span of overlap with the GRACE data (April 2002 through December 2003). Indeed other available global ocean data bases (e.g., Willis et al., 2004, Levitus et al., 2005) provide only yearly-mean temperatures. We have computed monthly steric sea level maps by vertically integrating density anomalies based on the Ishii et al. (2006) temperature anomalies, through the equation of state of sea water (see Lombard et al., 2005a). The monthly steric sea level data were further spatially averaged between $60^{\circ} \mathrm{S}$ and $60^{\circ} \mathrm{N}$, using equi-area weighting. The resultant time series is denoted by $\mathrm{GMSL}_{\text {steric }}$ and is shown in Fig.2. Error bars of the monthly values are crudely estimated to be \pm 5 $\mathrm{mm}$, based on the errors provided in Ishii et al., 2006, for the annual means. The corresponding best fitting annual sinusoid has an amplitude of $5.3 \mathrm{~mm}$ and a phase of $101.4^{\circ}$ (maximum on 10 April). The amplitude agrees very well with that of the WOA94 climatology, while a $22^{\circ}$ phase difference is noted. The latter difference is probably due to the difference in time span between the two different data sets.

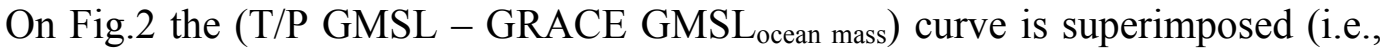
Fig.1c). We observe a good agreement between the two curves, within the error bars, for all studied months, with two exceptions: November 2002 and February 2003. The annual amplitudes of the two signals also show a very good agreement, with only $1 \mathrm{~mm}$ difference (see Table 1). As far as the phases are concerned, we note a $30^{\circ}$ difference, with the phase of (T/P GMSL - GRACE GMSL $_{\text {ocean mass }}$ ) closely coinciding with the phase of the steric sea level deduced from the WOA94 climatology. This result validates the applied methodology, which allows us to estimate steric sea surface height variations independently from in situ hydrographic data. 


\section{Conclusion}

In this study, we combined GMSL data from T/P altimetry and GRACE data averaged over the same oceanic domain $\left(60^{\circ} \mathrm{N}-60^{\circ} \mathrm{S}\right)$ and compared the difference time series to the steric sea level estimated over the same time span (and same oceanic domain) from in situ hydrographic data. An overall good agreement between the two data sets has been noticed. However the observed steric sea level and that deduced from T/P-GRACE do not exactly coincide. Several reasons may be invoked: (1) errors of the different data sets, (2) deep ocean contribution, not accounted for in the thermal expansion curve (based on the upper $700 \mathrm{~m}$ ocean layer), and (3) effect of salinity. However, the annual cycle of thermal expansion mainly occurs in the upper ocean layers $(0-500 \mathrm{~m})$, so that unaccounted deep thermal expansion is unlikely to be large. The effect of salinity on the GMSL is negligible compared to thermal expansion, on interannual to decadal time scales (Antonov et al., 2002, Ishii et al., 2006). To check whether on annual time scale, the salinity contribution to sea level is also negligible in terms of global mean, we have also estimated the $\mathrm{GMSL}_{\text {steric }}$ signal accounting for both temperature and salinity, using for the latter, the monthly salinity variations of a standard year based on the WOA01 climatology. In that case, a negligible difference of $0.2 \mathrm{~mm}$ and $1.2^{\circ}$ was observed in the annual amplitude and phase, respectively. Besides, the salinity curve does not show any annual signal. Finally data errors, both in GRACE data and in the steric sea level, may be the dominant factors explaining the phase difference between the T/P-GRACE curve and the steric sea level. For the latter, poor sampling of the southern oceans may be the largest source of uncertainty. The fact that the phase of the T/P-GRACE curve agrees well with the mean steric sea level curves based on ocean temperature climatologies (which provide better coverage of the oceans over the long time spans of data averaging) suggests that this is indeed the case.

It is important to emphasize that the maximum of the ocean mass and steric annual GMSL cycles are shifted by about $150^{\circ}-180^{\circ}$ (5-6 months). A similar behaviour has also been observed in previous studies of the global ocean (Chen et al., 1998, Minster et al., 1999, Cazenave et al., 2000), as well as in local studies like that of the Mediterranean Sea (Garcia et al., 2006). This difference in phase means that the water budget of the ocean is at a minimum when the steric sea level, and thus the heat content in the ocean, is at a maximum. Depending on the estimate, the maximum $\mathrm{GMSL}_{\text {steric }}$ is reached between $72.7^{\circ}$ (mid-Mars) and $101.4^{\circ}$ (early-April), following the austral 
summer when the heat stored is at a maximum in the southern ocean. The annual cycle of the ocean mass variation results mainly from land water storage variations, plus a small contribution from the atmospheric water vapour (Chambers et al., 2004, Chen et al., 1998, Minster et al., 1999, Cazenave et al., 2000, Milly et al. 2003). These studies, based on comparisons between T/P GMSL (corrected for steric effects) and global land model outputs, showed that seasonal change in the snow pack is the main driver of the annual ocean mass variation. But in addition, Ngo-Duc et al. (2005), showed that underground water stored in the major tropical basins (Amazon, Congo, etc.) in response to seasonal precipitation plays a non negligible role.

The present study is limited to a very short time span of less than 2 years. However when the GRACE time series extends in the future, this approach will provide new information on the global ocean heat content change, with important perpectives on a better estimate of the oceans' contribution to the net radiative imbalance of the Earth's climate system (Levitus et al., 2005) and to sea level rise.

Acknowledgements. We are very grateful to S. Bettadpur and F. Fletchner from the GRACE project for clarifications about the GRACE data processing. We also thank D. Chambers, J.M. Lemoine and F. Lyard for helpful discussions about the GRACE and T/P inverted barometer correction. Finally we are grateful to C.Cox from GSFC/NASA for supplying J2 SLR time series. This study is part of David Garcia's PhD dissertation.

\section{References}

Antonov, J.I., S. Levitus, and T.P. Boyer (2002): Steric sea level variations during 1957-1994: Importance of salinity. Journal of Geophysical Research, 107 (C12), 8013, doi:10.1029/2001JC000964.

AVISO/Altimetry (1996), AVISO user handbook for merged TOPEX/Poseidon products, AVI-NT-02-101, Edition 3.0. Available at www.aviso.oceanobs.com.

Bettadpur, S. (2004a), GRACE 327-734, Level-2 Gravity field product user handbook, online available from http://podaac.jpl.nasa.gov/grace/documentation test.html.

Bettadpur, S. (2004b), GRACE 327-742, UTCSR Level-2 Processing Standards Document for Level-2 Product Release 0001, online available from http://podaac.jpl.nasa.gov/grace/documentation test.html. 
Cazenave, A., F. Remy, K. Dominh and H. Douville (2000), Global ocean mass variations, continental hydrology and the mass balance of Antarctica ice sheet at seasonal timescale, Geophys. Res. Lett., Vol. 27, No. 22, 3755-3758.

Cazenave, A, and R. S. Nerem (2004), Present-day sea level change: Observations and causes, Reviews of geophysics, 42, RG3001.

Chambers, D. P., J. Wahr and R. S. Nerem (2004), Preliminary observations of global ocean mass variations with GRACE, Geophys. Res. Lett., Vol. 31, L13310.

Chao, B. F (2005), On inversion for mass distribution from global (time-variable) gravity field, J. Geodynamics, 39, 223-230, doi:10.1016/j.jog.2004.11.001.

Chen, J. L., C. R. Wilson, D. P. Chambers, R. S. Nerem and B. D. Tapley (1998), Seasonal global water mass budget and mean sea level variations, Geophys. Res. Lett., $32,19,3555-3558$.

Chen, J. L., C.R. Wilson, R. J. Eanes and R. S. Nerem (1999), Geophysical interpretation of the observed geocenter variations, J. Geophys. Res., 104, B2, 26832690.

Church J. A., J. M. Gregory, P. Huybrechts, M. Kuhn, K. Lambeck, M. T. Nhuan, D. Qin and P. L. Woodworth (2001), Changes in Sea Level, Climate Change 2001: The Scientific Basis, eds. Houghton and Ding, Cambridge Univ. Press.

Church J. A., N.J. White, R. Coleman, K. Lambeck and J. Mitrovica (2004), Estimates of the regional distribution of sea level rise over the 1950-2000 period, J; climate, 17, 2609-2625.

Cox, C. and B. F. Chao (2002), Detection of a large-scale mass redistribution in the terrestrial system since 1998, Science, 297.

Flechtner, F. (2003), GRACE AOD1B Product description document, online available from http://podaac.jpl.nasa.gov/grace/documentation_test.html. 
Garcia, D., B. F. Chao, J. Del Rio, I. Vigo and J. Garcia-Lafuente (2006), On the steric and mass-induced contributions to the annual sea level variations in the Mediterranean Sea, J. Geophys. Res., in press.

Holgate S. J., and P. L. Woodworth (2004), Evidence for enhanced coastal sea level rise during the 1990s, Geophys. Res. Lett., 31, L07305.

Ishii, M., M. Kimoto, and M. Kachi (2003), Historical ocean subsurface temperature analysis with error estimates, Monthly Weather Rev., 131, 51-73.

Ishii, M., M. Kimoto, K. Sakamoto, and S.I. Iwasaki (2006): Steric sea level changes estimated from historical ocean subsurface temperature and salinity analyses. Journal of Oceanography, 62 (2), 155-170.

Leuliette, E. W., R. S. Nerem, and G. T. Mitchum (2004), Calibration of TOPEX/Poseidon and Jason altimeter data to construct a continuous record of mean sea level change, Mar. Geod., 27, 79- 94.

Levitus, S., R. Burgett and T. P. Boyer (1994), World Ocean Atlas, vol.3, 4.

Levitus, S., J. Antonov, and T. Boyer (2005), Warming of the world ocean, 1955-2003, Geophys. Res. Lett., 32, L02604.

Lombard A., A. Cazenave, P.Y. Le Traon and M. Ishii (2005a), Contribution of thermal expansion to present-day sea level rise revisited, Global and Planetary Change, 47, 116.

Minster, J. F., A. Cazenave, Y. V. Serafini, F. Mercier, M.C. Gennero and P. Rogel (1999), Annual cycle in mean sea level from Topes-Poseidon and ERS-1: inference on the global hydrological cycle, Global and Planetary Change, 20, 57-66.

Milly, P. C. D., A. Cazenave, and M. C. Gennero (2003), Contribution of climate-driven change in continental water storage to recent sea-level rise, Proc. Natl. Acad. Sci. U. S. A., $100,13,158-13,161$. 
Nerem, R.S., and G.T. Mitchum (2001) Sea Level Change, in Satellite altimetry and Earth sciences, Fu and Cazenave, Ed., Academic Press, San Diego.

Ngo-Duc T., Laval K., Polcher Y and Cazenave A., Analyses of the contribution of continental water to sea level variations during the 1997-1998 ENSO event; Comparison between the AMIP simulations and the Topex/Poseidon satellite data., $J$. Geophys. Res., 110, D09103, doi:10.1029/2004JDO04940, 2005.

Ramillien G., Frappart F. and Cazenave A., (2005), Change in land water storage from 2 years of GRACE satellite data, Earth and Planetary Science Letters, 235, 283-301.

Rowlands, D. D., S. B. Luthcke, S. M. Klosko, F. R. Lemoine, D. S. Chinn, J. J. McCarthy, C. M. Cox and O. B. Anderson (2005), Resolving mass flux at high spatial and temporal resolution using GRACE intersatellite measurements, Geophysical Research Letters, Vol. 32 L04310.

Schmidt R., Flechtner F., Reigber Ch., Schwintzer P., Gunter A., Doll P., Ramillien G., Cazenave A., Petrovic S., Jochman H. and Wunsch J., (2005), GRACE observations of changes in continental water storage, Global and Planetary Change, in press.

Swenson, S. and J. Wahr (2002), Methods for inferring regional surface-mass anomalies from Gravity Recovery and Climate Experiment (GRACE) measurements of timevariable gravity, J. Geophys. Res., 107, B9, 2193, doi:10.1029/2001JB000576.

Tapley, D. B., S. Bettadpur, M. Watkins and C. Reigber (2004a), The gravity recovery and climate experiment: Mission overview and early results, Geophys. Res. Lett., 31 L09607.

Tapley, D. B., S. Bettadpur, J. C. Ries, P. F. Thompson and M. M. Watkins (2004b), GRACE Measurements of Mass Variability in the Earth System, Science, 305.

Wahr, J., M. Moleenar and F. Bryan (1998), Time variability of the Earth's gravity field: Hydrological and oceanic effects and their possible detection using GRACE, $J$. Geophys. Res., 103, B12, 30205-30229. 
Wahr, J., S. Swenson, V. Zlotnicki and I. Velicogna (2004), Time-variable gravity from GRACE: First results, Geophys. Res. Lett., Vol. 31, L11501.

Willis, J. K., D. Roemmich, and B. Cornuelle (2004), Interannual variability in upper ocean heat content, temperature, and thermosteric expansion on global scales, $J$. Geophys. Res., 109, C12036. 


\begin{tabular}{|l|c|c|}
\cline { 2 - 3 } \multicolumn{1}{c|}{} & Annual amplitude $(\mathrm{mm})$ & Annual Phase $\left(^{\circ}\right)$ \\
\hline (T/P GMSL $\left( \pm 60^{\circ}\right)$ & $6.1 \pm 1.2$ & $309.7 \pm 11.3$ \\
\hline GRACE GMSL & $10.9 \pm 1.1$ & $276.5 \pm 7.8$ \\
\hline$\left(\mathrm{T} / \mathrm{P}\right.$ GMSL mass $\left( \pm 60^{\circ}\right)$ & $6.4 \pm 2.1$ & $72.7 \pm 22.3$ \\
\hline GMSL $_{\text {steric }}\left( \pm 60^{\circ}\right)$ & $5.3 \pm 1.0$ & $101.4 \pm 11.3$ \\
\hline
\end{tabular}

Table 1. Annual amplitudes and phases of the best fitting sinusoids to the time series shown in Figs. 1 and 2. The phase $\varphi$ is defined in degrees from 1 January using a cos $(2 \pi t / T-\varphi)$ definition ( $2 \pi / T$ is the annual frequency and $t$ is time). Adjustments are performed over the April 2002-December 2003 time span. 
Figures:
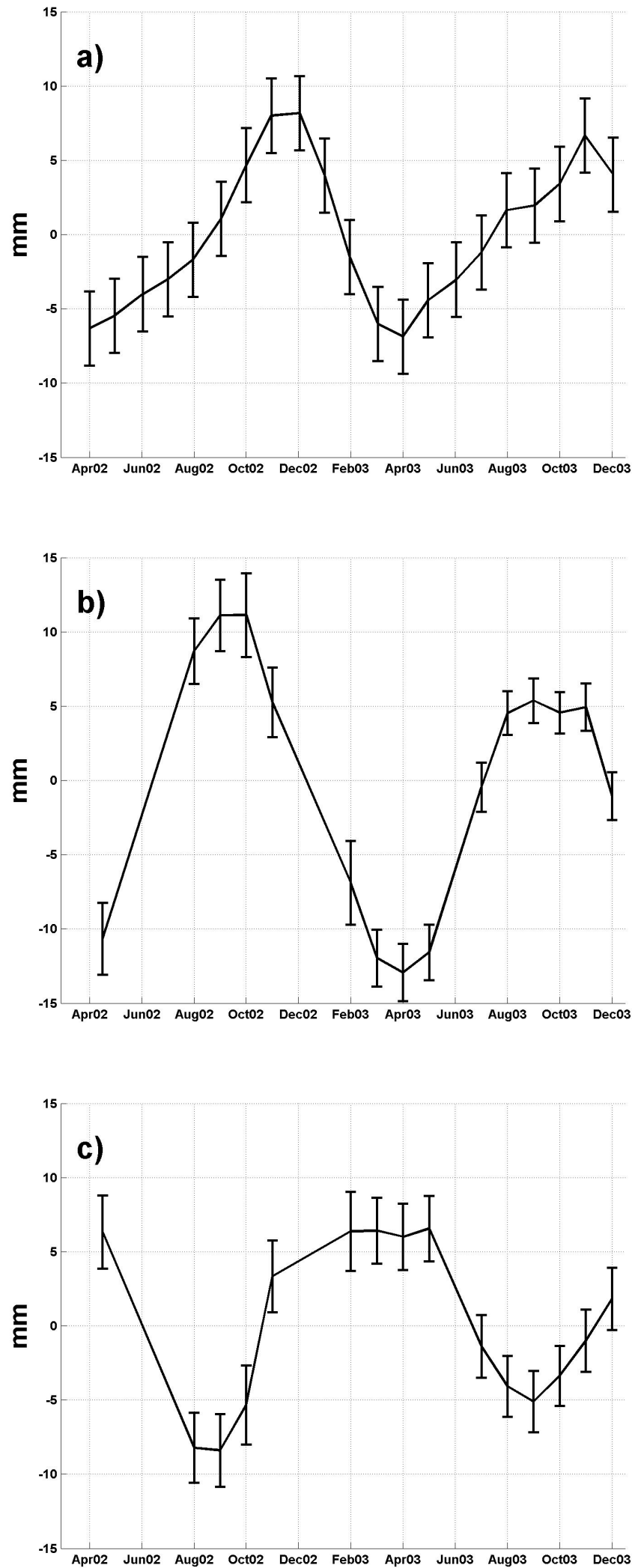

Fig.1: Global mean sea level (GMSL) over 2002-2004. (a) T/P GMSL. (b) . GRACE GMSL $_{\text {ocean mass. }}$ (c) (T/P GMSL -GRACE GMSL ocean mass $)$ 


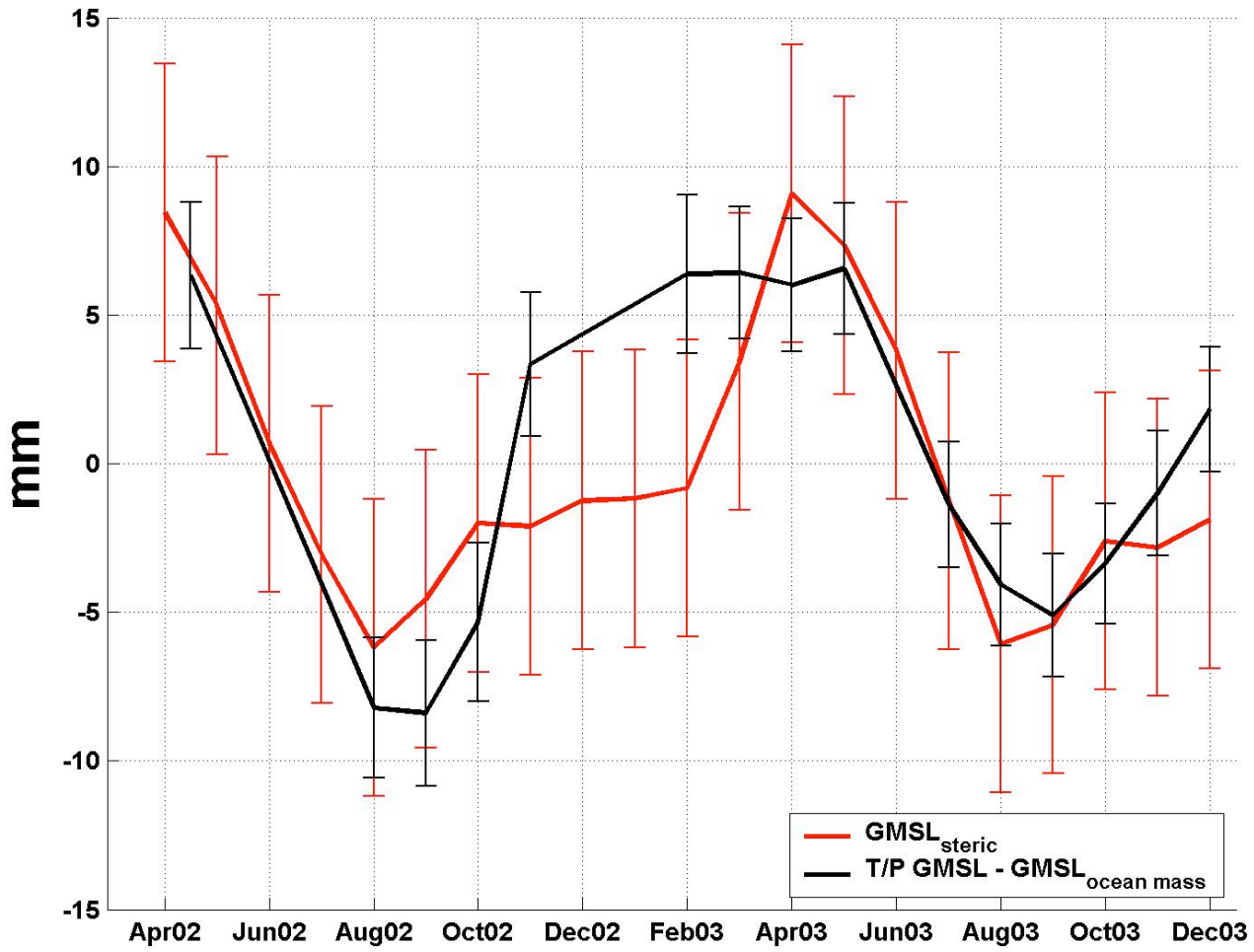

Fig.2: Red curve: Steric sea level based on Ishii et al. (2006) data; black curve: (T/P GMSL - GMSL ocean mass ). 